\title{
YAPILARIN DEPREM RİSKİNIN SOKAK TARAMA YÖNTEMİ İLE BELİRLENMESİ: SİVRİHİSAR ÖRNEĞİ
}

\author{
Ersin GÜLER ${ }^{1 *}$, Mehmet CANBAZ² $^{2}$ \\ ${ }^{1}$ Eskişehir Osmangazi Üniversitesi, Sivrihisar Meslek Yüksek Okulu, İnşaat Teknolojisi Bölümü, Eskişehir, \\ ORCID No : http://orcid.org/0000-0002-5679-8838 \\ ${ }^{2}$ Eskișehir Osmangazi Üniversitesi, Mühendislik Mimarlık Fakültesi, İnşaat Mühendisliği Bölümü, 26480, Eskişehir. \\ ORCID No : http://orcid.org/0000-0002-0175-6155
}

\begin{tabular}{|c|c|}
\hline Anahtar Kelimeler & Öz \\
\hline $\begin{array}{l}\text { Sivrihisar, } \\
\text { Sokak taraması, } \\
\text { Deprem, } \\
\text { Risk. }\end{array}$ & 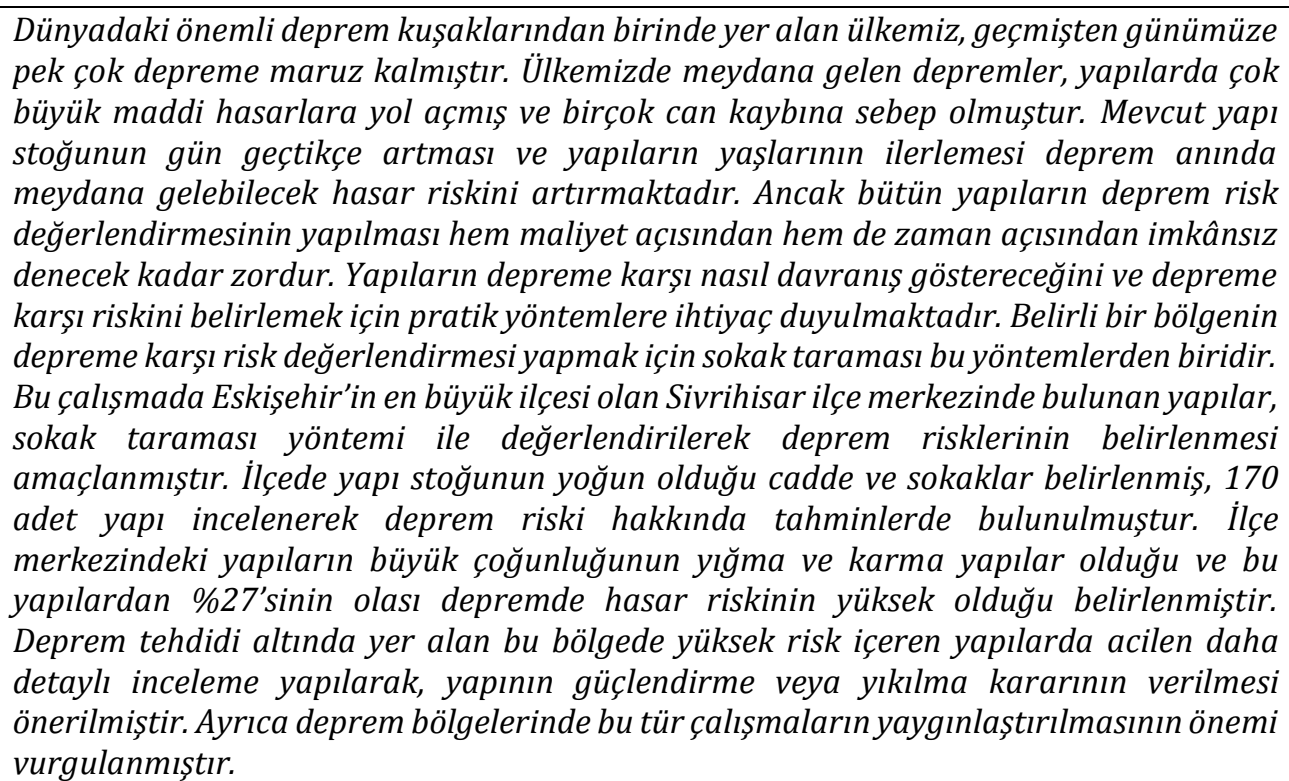 \\
\hline
\end{tabular}

\section{DETERMINATION OF EARTHQUAKE RISK OF STRUCTURES BY} STREET SCREENING METHOD

\begin{tabular}{l} 
Keywords \\
\hline Sivrihisar, \\
Rapid Visual Screening (RVS) \\
Method, \\
Earthquake, \\
Risk.
\end{tabular}
\begin{abstract}
Turkey is located in one of the major earthquake zone, has been exposed to many earthquakes from past to present. Earthquakes have caused big damage in buildings and numerous deaths in Turkey. The increase in the existing building stock day by day and the aging of the buildings rise the risk of damage occuring during an earthquake. However, earthquake risk assessment of all structures is difficult in terms of both cost and time. Practical methods are needed to determine structural response to earthquakes and their seismic risks. Street screening is one of these methods to evaluate the seismic risks in a particular region. In this study, it is aimed to determine the earthquake risks by evaluating with street screening method the structures located in Sivrihisar district center, the biggest district of Eskişehir. Streets and alleys with dense building stock in the district has been determined, 170 buildings have been examined and speculated about earthquake risk. It is determined that the majority of the buildings in the district center are masonry and mixed structures, and 27\% of these structures have a high risk of damage in the possible earthquake. In this region, which is under the threat of earthquake, it is recommended to make more detailed investigations in high-risk buildings and to decide whether to strengthen or demolish the building. In addition, the importance of enlarging such studies in earthquake zones is emphasized.
\end{abstract}

\footnotetext{
* Sorumlu yazar; e-posta : eguler@ogu.edu.tr
} 


\begin{tabular}{llll}
\hline Araştırma Makalesi & & Research Article & \\
Başvuru Tarihi & $: 12.05 .2020$ & Submission Date & $: 12.05 .2020$ \\
Kabul Tarihi & $: 16.07 .202$ & Accepted Date & $: 16.07 .2020$ \\
\hline
\end{tabular}

\section{Giriş}

Dünyadaki önemli deprem kuşaklarından birinde yer alan ülkemiz, geçmişten günümüze pek çok depreme maruz kalmıştır ve bu depremler nedeniyle ülkemizde yıkıcı etkileri olmuş, çok büyük maddi hasarlara yol açmış ve birçok can kaybına sebep olmuştur (Ergünay 2007; Sesetyan, Demircioğlu, Duman, Çan, Tekin, Azak ve Fercan 2018; Güler ve Afacan 2019). Türkiye nüfusunun büyük bölümünün büyük şehirlerde yașaması ve nüfusunun \%95'inin önemli deprem bölgelerinde yaşıyor olması riski artırmaktadır. (Ünal ve Yurtçu 2006). Ancak sanayileşmenin artması, kırsaldan kente göçün hızlı olması vb. etkiler sonucunda hem ilçelerde hem de kentlerde bu hızlı nüfus artışı olmuş, çarpık yapılaşmayı beraberinde getirmiş ve düzgün yapılaşma gerçekleştirilememiştir (Akbulut ve Aytuğ 2005). Bu nedenle yapıların gerekli standartları sağlamadığı ve pek çok yerleşim yerinin risk altında olduğu düşünülmektedir. Günümüzde kentsel dönüșüm çalışmalarının hızlanması bu yapı stoğunu eritmeye yönelik olsa da yeni risk alanlarının belirlenmesi gerekmektedir. Muhtemel bir depremde kentlerin ne derece hazır olduğu ve yapılardaki sorunların belirlenerek önceden çalışmalar yapılması gerekmektedir. Dolayısıyla deprem öncesi yapılacak çalışmalar günümüzde önem kazanmış ve hızlanmıştır. (Şenel, İnel, Toprak ve Manav 2007; Güler, Canbaz ve Şengel 2019).

Kuzey Anadolu Fay Hattı (KAFH) ülkemizdeki önemli fay hatlarından biridir. Bu hat üzerinde doğudan batıya doğru tektonik hat birbirini tetikleyerek depremler meydana gelmektedir (Zabcı, Akyüz, Karabacak, Sançar, Altunel, Gürsoy ve Tatar, 2011;Fraser, Hubert Ferrari, Verbeeck, Moreno, Avsar, Maricq, Coudijzer, Vlamynck ve Vanneste 2012; Hubert Ferrari, Avsar, Ouahabi, Lepoint, Martinez ve Fagel, 2012; Duman ve Emre, 2013; Zabcl, Altunel, Akyüz, 2017).

1999 yılında meydana gelen Düzce ve Marmara depremleri bunun en yakın örnekleridir. Bu fay hattına yaklaşık 100 km uzaklığında bulunan Eskişehir ili de bu depremlerden etkilenmiştir. Eskişehir ve çevresi incelendiğinde son yüzyll içerisinde farklı tarihlerde ve farklı büyüklüklerde depremler meydana geldiği görülmüştür. (Altunel ve Barka, 1998). Ülkemizin önemli sanayi şehirlerinden olması nedeniyle Eskişehir'de depreme karşı yapıların göstereceği davranış önemlidir.

Deprem bölgelerinde yer alan yapıların riskli bölgelerde yer alması, yapı stoğunun artması ve kentsel dönüşüm çalışmalarının artması ile riskli yapıların tespit edilmesi önem arz etmektir. Bu yapıların hem hızlı hem de daha ekonomik olarak belirlenebilmesi için sokak tarama çalışmaları önemlidir.

$\mathrm{Bu}$ çalışmada Eskişehir ili Sivrihisar ilçe merkezinde yapı stoğunun yoğun olduğu cadde ve sokaklar incelenerek yapıların deprem risklerinin belirlenmesi amaçlanmıştır. İlçenin tarihi yerleşim yerlerinden biri olduğu düşünülürse dayanıksız pek çok yapı olduğu tahmin edilmektedir. Bu amaçla hem yığma hem de karma yapılar incelenmiştir. Yapılan sokak taramasında yapılara belirli kriterlerle önce puan verilmiş ardından diğer risk faktörlerine göre belirli oranda bu puandan düşülmüştür. Yapıların risk değerlendirmesi yapılarak ön tahminde bulunulmuştur. Ancak kesin riskin belirlenmesi hem projesinin hem de laboratuvar sonuçlarının ardından belirlenmelidir. $\mathrm{Bu}$ çalışma sonucunda yapılardaki ön risk değerlendirmesi yapllarak hem zaman hem de maddi açıdan kazanç sağlanarak, hangi yapılarda öncelikle bu detaylı araştırmanın yapılması gerektiği önerilmiștir.

\section{Materyal ve Metot}

$\mathrm{Bu}$ çalışma etik kurul kararı gerektiren bir çalışma değildir. Çalışma bir kurumda yapılan uygulamayı kapsamamaktadır. Ayrıca araştırma ve yayın etiğine de uyulmuştur.

\subsection{Bölgenin Özellikleri}

Eskişehir merkezine 90 km uzaklıkta bulunan Sivrihisar ilçesi geçmişte birçok uygarlığa ev sahipliği yapmıştır. Aynı zamanda günümüzde Ankara, İzmir, Afyon illerine bağlantı noktasında bulunmaktadır (Şekil 1).

İlçenin topoğrafyası incelendiğinde kuzeye doğru eğim artmakta güneyinde ise düz bir alan görülmektedir. Genel jeolojisini graniyotidi, kırmızıbayır formasyonu, uruş formasyonu ve kuvaterner yaşlı alüvyonal birimler oluşturmaktadır (Bingöl, Akyürek ve Korkmazer, 1973; Gözler, Cevher ve Küçükyaman, 1984).

İlçede Çal Dağı'nın bir uzantısı olarak volkanik bir kaya kütlesi bulunmakta ve yapılaşma ilçenin kuzeyde yer alan yamacından düzlüğe doğru ilerlemektedir. Bu nedenle eski ve yeni yapılaşma zamanla ayrılmaktadır. Tarihi yapıların haricinde ilçede eski yapıların bulunduğu ve bölge halkı tarafından kullanımına devam ettiği bilinmektedir.

İlçede konut ve ticaret yapı stoğunun yanında Sivrihisar Ulu Camii, Ermeni Kilisesi gibi tarihi dini yapılarda bulunmaktadır. Bu yapıların etrafında konut ve ticari yapılanmaların çok olduğu görülmüştür. 


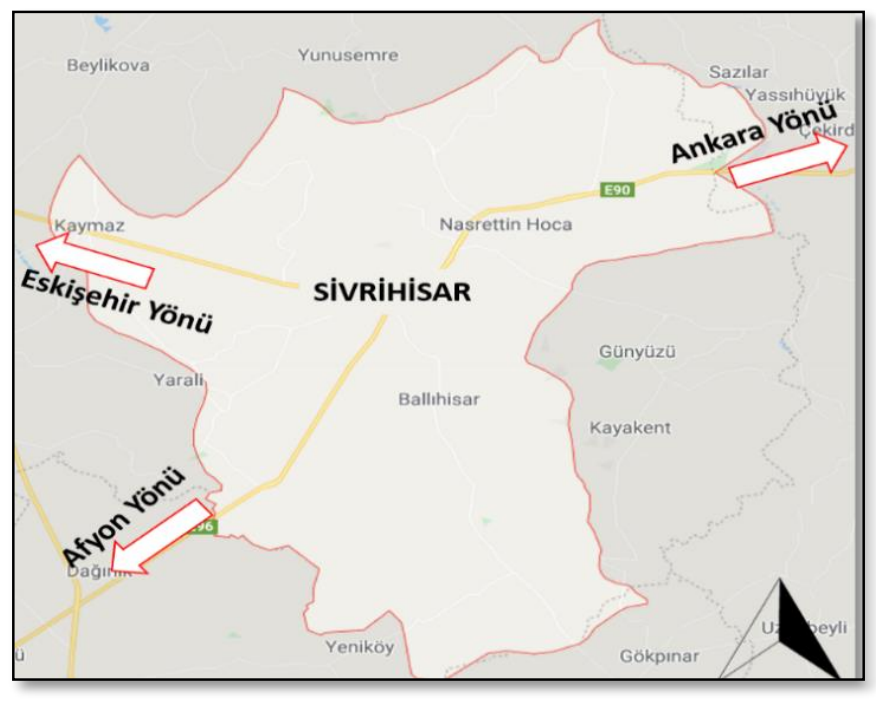

Şekil 1. Sivrihisar İlçe Sınırları (IKK-1)

\subsection{Sokak Taraması}

Bu çalışmada Eskişehir ili Sivrihisar ilçe merkezinde yapı yoğunluğunun fazla olduğu ve hem karma hem de yığma yapıların olduğu on iki adet cadde ve sokak seçilerek taranmış ve elde edilen veriler değerlendirilmiştir. İlçenin genel görünümü Şekil 2'de gösterilmiştir.

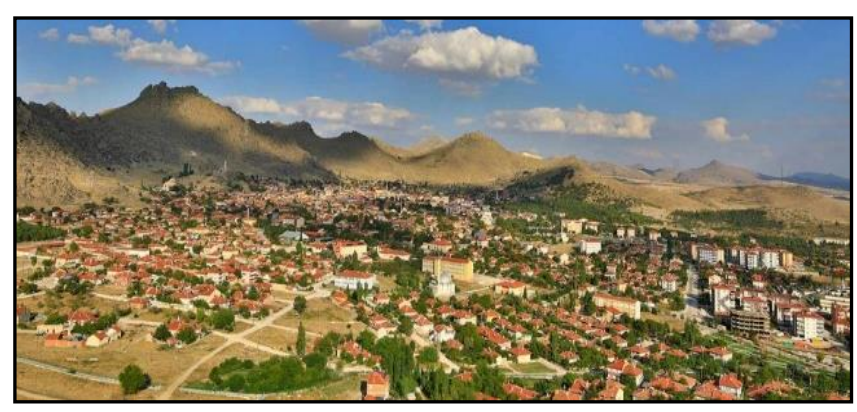

Şekil 2. İlçenin genel görünümü (İK-2).

Bir bölgenin deprem riskini belirlemek için tüm binaları detaylı incelemek mümkün olmamaktadır. Öncelikle bölgede hızlı bir tarama yapılması ve detaylı taramanın hangi yapılarda yapılması gerektiği belirlenmelidir. Bunun için hızlı tarama yöntemleri geliştirilmiş ve bölgedeki yapılar için ön risk değerlendirmesi yapılmaktadır. $\mathrm{Bu}$ yöntemlerden biri olan sokak taraması ile yapılara coğrafi konum, yerel zemin özellikleri, faya olan uzaklığına bağlı olarak hız bölgesi puanı belirlenmektedir. Çalışmada incelenen binalar öncelikle kat sayıları ve hız bölgelerine göre bir puan almakta ve her olumsuz durum için belirli parametreler göz önüne alınarak puanları azalmaktadır (Albayrak, Canbaz ve Albayrak 2015). Çalışmada ilçe merkezinde belirlenen cadde ve sokaklarda yapılan tarama ile her bina gözlemsel olarak incelenmiş ve Tablo 1 doldurulmuștur. Tablodaki 1, 2, 3 gibi sayılar incelenen yapıların numaralarını göstermektedir.

Tablo 1

Yapı Değerlendirme

\begin{tabular}{lllll}
\hline & $\mathbf{1}$ & $\mathbf{2}$ & $\mathbf{3}$ & $\ldots$ \\
\hline TÜRÜ & & & & \\
YAPI YAŞI & & & & \\
KAT SAYISI & & & & \\
DUVAR/BOŞLUK & & & & \\
DUVAR-BOŞLUK DÜZENİ & & & & \\
ÇARPIŞMA DURUMU & & & & \\
TOPOGRAFYANIN ETKISİ & & & & \\
GÖRÜNÜR BİNA KALİTESİ & & & & \\
\hline
\end{tabular}

Türü: Normal bodrum kat için kullanılan malzemeler Tablo 2'deki gibi belirtilmektedir. Türü kısaltılırken 2B, 1C, OD gibi iki etki birlikte kullanılır.

Tablo 2

Taşıyıcı Yapı Malzemesi

\begin{tabular}{lclc}
\hline \multicolumn{1}{c}{ Normal Kat } & \multicolumn{2}{c}{ Bodrum Kat } \\
\hline $\begin{array}{l}\text { Tassıyıcı Duvar } \\
\text { Malzemesi }\end{array}$ & No & $\begin{array}{l}\text { Taşıııı Duvar } \\
\text { Malzemesi }\end{array}$ & No \\
\hline Boşluklu tuğla & 1 & Taş & A \\
Gaz beton & 2 & Betonarme & Buvar \\
Beton briket & 3 & Tuğla & C \\
Taş & 4 & Beton briket & D \\
Kerpiç & 5 & Kerpiç & E \\
Ahşap & 6 & Farklı bir & F \\
Farklı bir malzeme & 7 & & \\
\hline
\end{tabular}

Yapı Yaşı: Yapının statik projesi yapılırken yürürlükte olan deprem yönetmeliği etkilidir. Ayrıca o yıllardaki yapım tekniklerinin risk belirlenmesinde etkisi vardır.

Kat Sayısı: Binanın toplam kat sayısı olarak belirlenir. Ancak bazı kademeli binalarda, kat sayısının fazla olduğu kısım dikkate alınmıştır. Binada çatı, bodrum katı veya asma kat olması durumunda normal kat gibi değerlendirilmiştir.

Duvar/Boşluk: Binaların iki cephesi birden değerlendirildiğinde, genelde binaların sokağa bakan cephelerinde kapı ve pencere boşluklarının fazla olduğu görülmüștür. $\mathrm{Bu}$ nedenle bina yüzeyi incelenerek cephedeki kapı ve pencere boşluklarının toplam uzunluğa oranı değerlendirilmiştir. Bu oran iyi “ 0 ”, orta 
“1" ve kötü "2" şeklinde belirtilmiştir. Bu değerler için; boşluk uzunluğu toplam uzunluğun üçte birinden az ise iyi, üçte ikisinden fazlaysa kötü arasında ise orta olarak dikkate alınmıştır.

Duvar-Boşluk Düzeni: Duvarların taşıyıcı olarak kullanıldığı yapılarda boşluklar üst üste gelmesi önemlidir. Bu durum "iyi" olarak dikkate alınmıștır. Boşluklar üst üste gelmemesi ise düzensiz yani "kötü" bir durum olarak ifade edilmektedir. Aradaki durumlar ise az düzenli yani "orta" durumdur. Bu duvar boşluk düzeni için değerlendirme iyi " 0 ", orta " 1 " ve kötü " 2 " şeklinde belirtilmiştir.

Çarpışma Durumu: Özellikle bitişik nizam yapılarda iki yapının döşemelerinin aynı hizada olmaması durumunda çarpışma etkilidir. Çarpışma durumu için farklı kat seviyeleri var ise etkili olduğunda "1", kat seviyeleri aynı hizada ise etkili olmadığında " 0 " olarak dikkate alınmıştır.

Topoğrafyanın Etkisi: İncelenen yapının konumu tepede veya otuz dereceden fazla bir eğime sahip ise topografyanın etkisi dikkate alınır. Etki dikkate alınıyorsa "1", alınmıyorsa “0" olarak belirlenmiștir.

Görünür Bina Kalitesi: Binanın göz ile kalitesinin belirlenmesidir. Burada dikkat edilen binanın yapımındaki işçilik ve malzeme kalitesidir. Yapının görünür kalitesi kötü "2", orta "1" ve iyi "0" şeklinde belirtilmiştir.

Bu risk faktörleri dışında ağır çıkma, yumuşak kat, zayıf kat, plan düzensizliği gibi birçok parametrede önemli olmasına rağmen özelikle incelenen yığma ve karma yapı stoğunda dikkate değer bir şekilde karşılaşılmadığı için değerlendirme dişında tutulmuştur.

Hız Bölgesine Ait Puanlar: Yapıların deprem esnasında uğradıkları sarsıntının şiddeti en çok yapının faya olan uzaklığı ile üzerinde bulunduğu yerel zeminin özelliklerine bağlıdır. Bu nedenle deprem risk haritaları mikro bölge ölçeğinde hazırlanırken bu iki parametreyi de içerecek biçimde yapılmaktadır. Zeminin kayalık olduğu, oluşabilecek deprem büyüklügünün 5,5 olabileceği ve mevcut kırıklara uzaklığın $20 \mathrm{~km}$ civarında olabileceği dikkate alındığında peak ground velocity (PGV) - peak ground acceleration (PGA) oranı 44 (cm/sn)/g olur (Campbell vd, 2008; Wald, 1999). PGA'nın 0.3 g olarak dikkate alınması durumunda PGV $13.2 \mathrm{~cm} / \mathrm{sn}$ şeklinde hesaplanabilir. Hesaplanan PGV, 10 $\mathrm{cm} / \mathrm{sn}$ ile $20 \mathrm{~cm} / \mathrm{sn}$ aralığında olduğundan VI hız bölgesine düșer. Bu bölgede yapı kat sayısına göre puanlar 100 ile 160 arasında dikkate alınmıştır (Albayrak vd 2015). Yapıların puan hesabında Tablo 3 dikkate alınmıştır. Örnek değerlendirme Şekil 3'te gösterilmiştir.

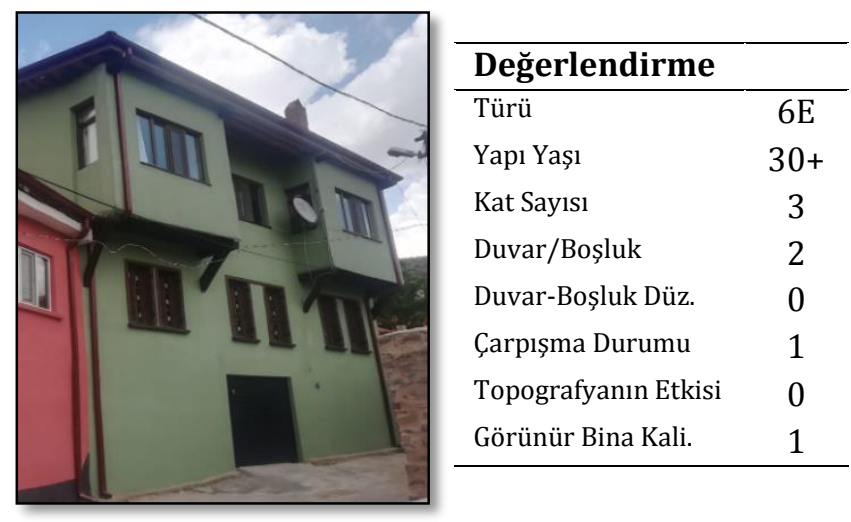

Şekil 3. Örnek Değerlendirme

Tablo 3

İncelenen Binaların Değerlendirilmesi

\begin{tabular}{|c|c|c|c|c|c|}
\hline \multicolumn{3}{|c|}{ Kat Sayısı } & 1 & 2 & $3+$ \\
\hline \multicolumn{3}{|c|}{ Hız Bölgesi Puanı } & 160 & 140 & 100 \\
\hline \multicolumn{3}{|c|}{ Duvar/Bosluk } & 0 & -5 & -15 \\
\hline \multicolumn{3}{|c|}{ Duvar-Boșluk } & -5 & -10 & -15 \\
\hline \multirow{19}{*}{$\frac{y}{n}$} & Çarp & tkisi & 0 & -5 & -5 \\
\hline & Top & ik etki & 0 & -2 & -2 \\
\hline & Görü & oina kalitesi & -5 & -5 & -10 \\
\hline & \multirow{12}{*}{ 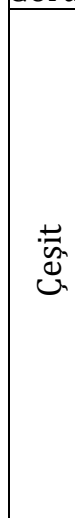 } & 0 & 0 & -10 & -15 \\
\hline & & 1 & 0 & -5 & -10 \\
\hline & & 2 & 0 & -10 & -15 \\
\hline & & 3 & -5 & -10 & -15 \\
\hline & & 4 & -5 & -10 & -15 \\
\hline & & 5 & -20 & -30 & -40 \\
\hline & & $6-7$ & -10 & -20 & -30 \\
\hline & & $\mathrm{A}$ & 0 & -5 & -10 \\
\hline & & B & 0 & 0 & 0 \\
\hline & & $\mathrm{C}$ & 0 & -5 & -10 \\
\hline & & $\mathrm{D}$ & -10 & -20 & -30 \\
\hline & & E-F & -20 & -30 & -40 \\
\hline & \multirow{4}{*}{$\begin{array}{l}\bar{\pi} \\
\vec{\tau} \\
\overline{0} \\
\bar{\sigma}\end{array}$} & $0-5$ & 0 & 0 & 0 \\
\hline & & $5-15$ & -5 & -5 & -5 \\
\hline & & $15-30$ & -5 & -10 & -15 \\
\hline & & $30+$ & -5 & -15 & -20 \\
\hline
\end{tabular}

Kat sayısına bağlı olarak hız bölgesi puanları verilmiştir. Her bir risk faktörü puanı daha önce görsel olarak belirlenen “ 0,1 , 2" değerleri ile çarpılarak elde edilen puanlar toplanmış ve bu olumsuzluklar hız bölgesi puanından çıkarılarak her bir yapı için güvenirlik indeksi belirlenmiştir. Riskin fazla olduğu durumlarda bina güvenilirlik indeksi negatif bulunabilmektedir. Bu durumda bina güvenirlik indeksi sıfır olarak dikkate alınmıştır. Bina güvenirlik indeksine bağlı risk değerlendirmesi Tablo 4'te verilmiştir. 
Tablo 4

Bina Güvenilirlik İndeksi

\begin{tabular}{ccccc}
$\begin{array}{c}\text { Bina } \\
\begin{array}{c}\text { Güv. } \\
\text { Indeksi }\end{array}\end{array}$ & $0<\mathrm{X} \leq 30$ & $30<\mathrm{X} \leq 70$ & $70<\mathrm{X} \leq 100$ & $100<\mathrm{X}<160$ \\
\hline Risk & Yüksek & Orta & Düşük & Yok \\
\hline
\end{tabular}

Bina güvenirlik indeksine bağlı risk değerlendirilmesinde örnek olarak Şekil 3'teki yapı ve değerlendirilmeleri dikkate alındığında yapılacak hesapta Tablo 3'ten yapının hız bölgesi puanın 100 olduğu belirlenmiștir. Risk faktörlerinden türü dikkate alındığında ahşap ve kerpiç kullanıldığından -40, duvarboşluk oranı -30 puan olarak dikkate alınabileceği, çarpışma durumu -5 , görünür bina kalitesinin ise -10 olarak dikkate alınabileceği, diğer risk faktörlerinin oluşmadığı dolayısı ile hız bölgesi puanından bu puanlar çıkarıldığında bu binanın güvenirlik indeksinin 15 olarak alınabileceği belirlenmiştir. Dolayısı ile Tablo 4'e göre bu bina yüksek riskli grupta yer almıştır.

\section{Bulgular}

Yapılan çalıșma kapsamında belirlenen bölgede 170 adet yapı incelenmiştir. Bu yapılara ait değerlendirme Tablo 5'te gösterilmiştir. Yapılaşma merkezden daha çok merkez çevresinde yoğunlaşmıştır.

Tablo 5

İncelenen Yapıların Değerlendirilmesi

\begin{tabular}{|c|c|c|c|c|c|c|c|c|c|c|c|c|c|c|c|c|}
\hline \multicolumn{3}{|c|}{ Yapı Yaşı } & \multicolumn{2}{|c|}{ Kat Sayısı } & \multicolumn{3}{|c|}{ Duvar/Boşluk } & \multicolumn{5}{|c|}{$\begin{array}{c:c}\text { Duvar-Boşluk Görünür Bina } & \text { Kalitesi } \\
\text { Düzeni } & \end{array}$} & \multicolumn{2}{|c|}{ Çarpışma } & \multicolumn{2}{|c|}{ Topoğrafya } \\
\hline $0-5$ & $5-15 \quad 15-30$ & $30+$ & 2 & $3+$ & iyi & orta & kötü & kötü & orta & iyi & kötü & orta iyi & Etkili & Etkisiz & Etkili & Etkisiz \\
\hline 0 & 17 & 151 & 7372 & 25 & 16 & 47 & 107 & 78 & 75 & 17 & 95 & 705 & 73 & 97 & 2 & 168 \\
\hline
\end{tabular}

Şekil 4'e göre yapı yaşları incelendiğinde yeni bina görülmezken, \%11'nin 30 yaşından küçük olduğu geri kalanın ise oldukça eski binalar olduğu belirlenmiştir. Dolayısıyla ilçe merkezinde kentsel dönüşümün uygulamalarının gerçekleşmediği söylenebilir.
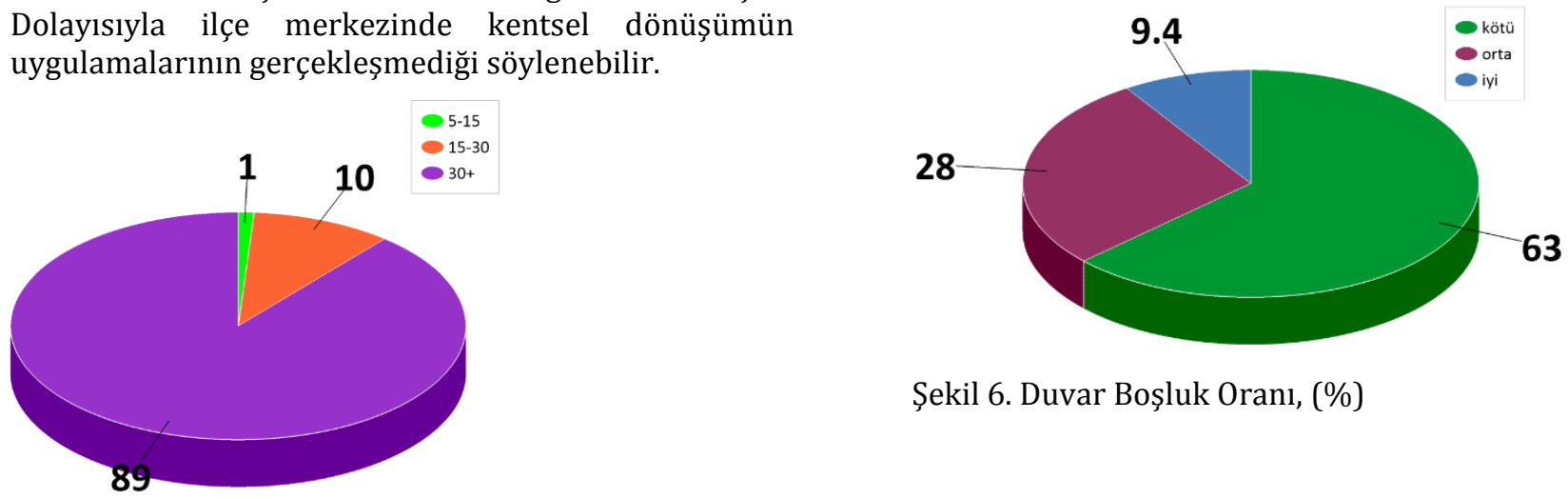

Şekil 6. Duvar Boşluk Oranı, (\%)
1999 depremleri sonrasinda yapılan incelemeler sonucunda binalardaki hasarın kat sayısıyla arttığ gözlenmiștir. Binalarda kat sayısının artması sonucunda kütle artmakta ve deprem etkisinin fazla olduğu görülmektedir. Ülkemizdeki pek çok yapının deprem yönetmeliklerine uygun olmadığı bilinmektedir. Dolayısıyla kat sayısı arttıkça depremlerde meydana gelecek hasar miktarının artacağı bilinmektedir. Şekil 5 incelendiğinde tek ve iki katlı yapılar \%85 oranında iken, geri kalan yapıların fazla kat sayısına sahip olması aynı zamanda taşıyıcı sisteminin duvar olması riski artırmaktadır.

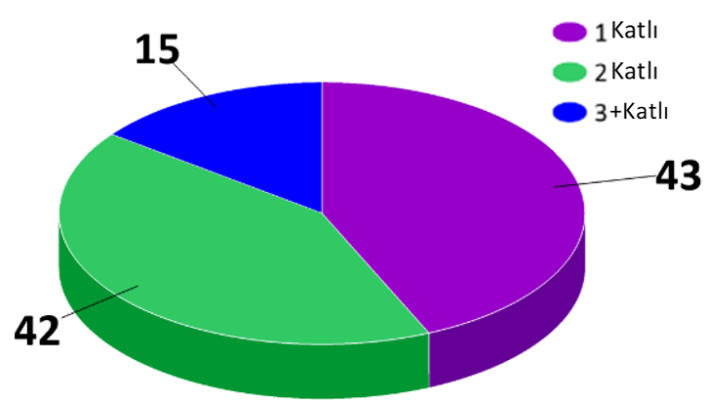

Şekil 5. Kat Sayısı, (\%)

Taşıyıcı sistemi duvar olan yapılarda çok fazla miktarda boşluk istenmez. Boşluk uzunluğunun toplam duvar uzunluğuna oranına oranı dikkate alınır. Bu orana göre yapıların değerlendirilmesi Şekil 6'da belirtilmiştir. Binaların \%63 gibi azımsanmayacak oranında boşlukların çok olduğu belirlenmiştir.

Şekil 4. Yapı Yaşı, (\%) 
Birden fazla kata sahip yapıların her katında mecburen bırakılan boşlukların aynı hizada olması depremde hasar görme ihtimalini azaltır. Yapıların duvar-boşluk düzeni incelenmiş ve Şekil 7'de değerlendirilmiştir. Yapıların \%46 gibi önemli bir kısmında boşlukların düzensiz dağıldığı belirlenmiştir.

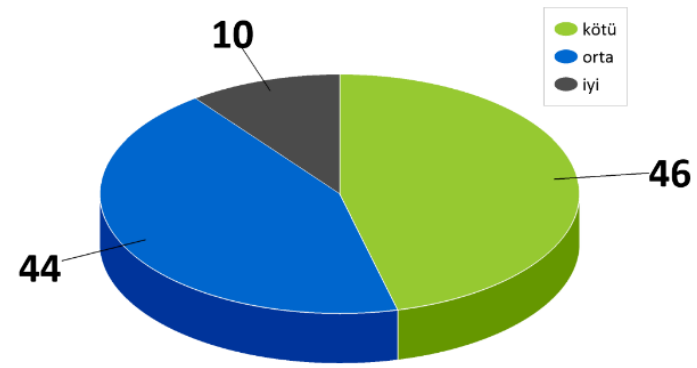

Şekil 7. Duvar Boşluk Düzeni, (\%)

Binalar belirli aralıklarla bakımının yapılması hizmet ömrünün kısalmaması için önemlidir. Özellikle deprem gibi afetlerde görünür yapı kalitesinin hasarda etkisi vardır. Şekil 8'e göre yapıların büyük kısmının görünür yapı kalitesinin iyi olmadığı görülmüştür.

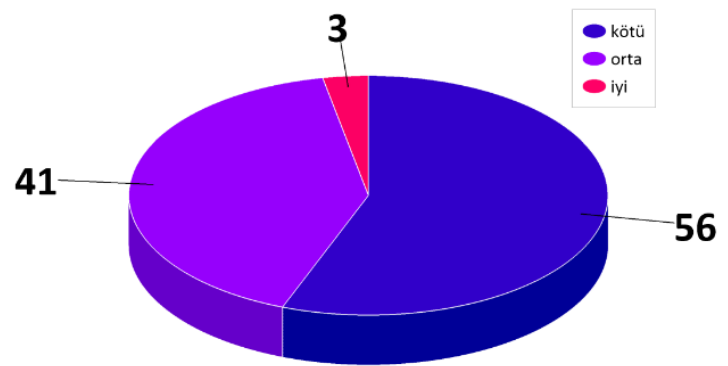

Şekil 8. Görünen Yapı Kalitesi, (\%)

Bitişik nizam olan yerlerde, binaların depreme karşı göstereceği performanslar değişmekte ve binalar birbirini etkilemektedir. Deprem nedeniyle binalar çarpışmakta ve üst katlarda artan oranda çatlaklar oluşabilmektedir. Şekil 9 incelendiğinde binaların \%57'sinde çarpışma riskinin olmadığı görülmüştür. İlçe merkezi yapılaşması düz bir alanda olduğundan topografyadan kaynaklı riskli bina oldukça azdır.

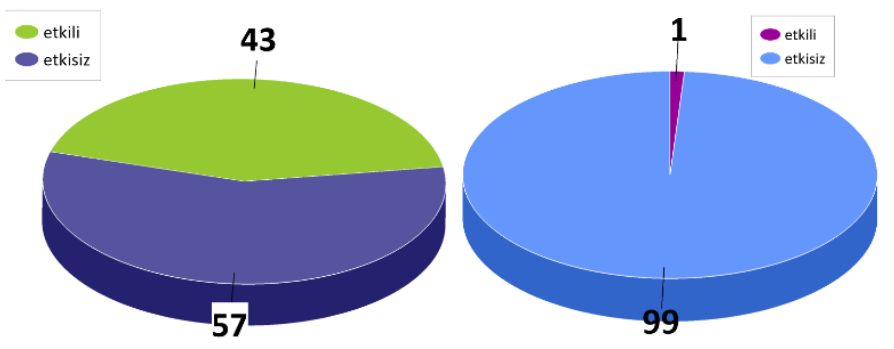

Şekil 9. Çarpışma Durumu ve Topoğrafyanın Etkisi
Taşıyıcı sistemde taşıyıcı duvar malzemesi dikkate alındığında incelenen yapıların \%18'nin duvar malzemesinin boşluklu tuğla olduğu, \%3'nün gaz beton olduğu, \%43'nün beton briket, \%4'nün taş, \%21'nin ahşap, \%11'nin ise farklı bir malzemeden yapıldığ belirlenmiştir.

Yapıdaki düzensizlik ve olumsuzluklara göre hesaplanan bina güvenirlik indeksleri ve riskler Şekil 10'da gösterilmiştir. Görsel olarak incelenen 170 yapının \%62'sinin depremde hasar riskinin olduğu, \%28 gibi oldukça yüksek kısmının da yüksek riske sahip olduğu görülmüştür. Albayrak ve diğ. (2015) tarafından yapılan çalışmada da benzer şekilde inceleme yapılan yapıların çoğunun yüksek riske sahip olduğu belirtilmiştir. Bu iki çalışmada Eskişehir'in yüksek riskli bina sayısı dikkat çekmektedir.

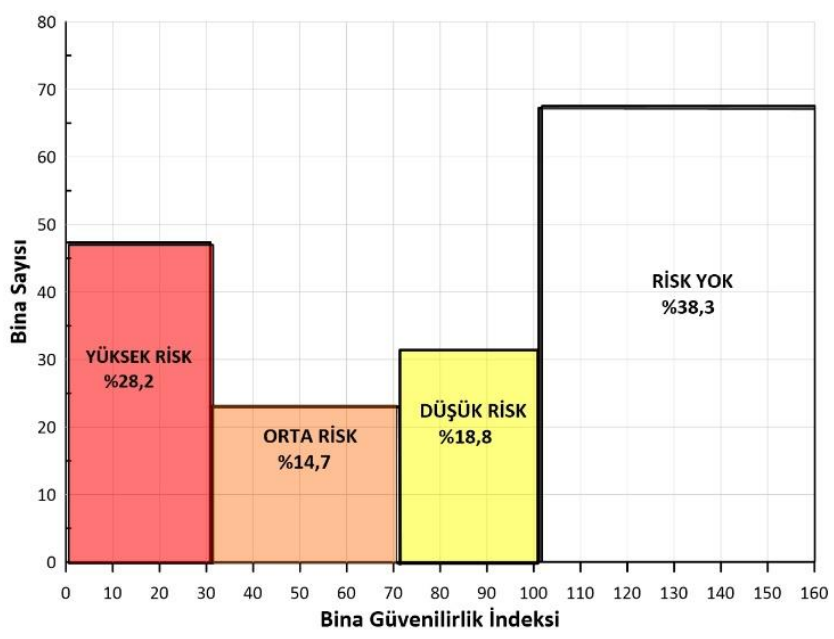

Şekil 10. İncelenen Yapıların Risk Değerlendirmesi

\section{Sonuç ve Öneriler}

Yapılan çalışma sonucunda 170 yapının yüzeysel incelenmesi sonucu:

- İlçe merkezinin kentsel dönüşüm ile eski binalarının yenilenmediği, yaş olarak eski binaların çokluğunun depremde genel hasar riskini arttırmaktadır.

- Taşıyıcısı duvar olan yapılarda 3 ve üzeri gibi yüksek kat sayısı özellikle depremde hasar riskini arttırmaktadır. Yapılan çalışmada yüksek katlı yapıların azımsanmayacak oranda olduğu görülmüştür.

- Taşıyıcı duvarlarda boşlukların az olması önemlidir. Ancak bu çalışmada yapıların üçte ikisinin fazla miktarda boşluk içerdiği belirlenmiştir.

- Birden çok kata sahip yapılarda boşluklar hizalı olmalıdır. Yapıların \%90 gibi büyük kısmında düzensizlik görülmüştür.

- Sokak taramasında binaların \%97'sinin görünür yapı kalitesinin iyi olmadığı görülmüştür. 
- Yapılaşma düz bir alanda olduğundan topografyanın etkisi yok denecek kadar azdır. Ancak çarpışma durumu incelendiğinde yapıların \%43'ünde bu riskin görüldüğü ifade edilebilir.

- Yapılan risk analizine göre binaların \%28'inin görsel olarak yüksek riske sahip olduğu acilen bu binaların daha detaylı incelenmesi, ölçümler ve testler ile yapının güçlendirme veya yıkılma kararının verilmesi gerekir.

$\mathrm{Bu}$ tür çalışmalar oldukça fazla sayıda olan yapı stokunun deprem gibi doğal afetler için riskinin belirlenerek, güçlendirme veya yıkma kararının verilebilmesi adına detaylı çalışmaların ve deneysel analizlerin hangi binalardan başlanmasını gerektiğini belirlemek için önemlidir. Bu tür çalışmalara 1999 depreminden sonra İstanbul'da bazı ilçelerde başlanmış olmasına rağmen devamı gelmemiștir. Ülkemizin aktif bir deprem ülkesi olduğu düşünüldügünde, bu tür çalışmaların oldukça önemli olduğu düşünülmektedir.

\section{Araştırmacıların Katkısı}

Bu araştırmada; Ersin GÜLER, bilimsel yayın araştırması, saha çalışması, makalenin oluşturulması; Mehmet CANBAZ, tasarımın yapılması, analizlerin yapılması, verilerin değerlendirilmesi, makalenin genel kontrolünün yapılması konularında katkı sağlamışlardır.

\section{Çıkar Çatışması}

Yazarlar tarafından herhangi bir çıkar çatışması beyan edilmemiștir.

\section{Kaynaklar}

Akbulut, M.T. ve Aytuğ, A. (2005). Deprem hasar görebilirlik riskinin gözleme dayalı belirlenmesine yönelik öneri değerlendirme yaklaşımı. MEGARON ,YTÜ Mim. Fak. E-Dergisi, 1(1), 88-98. Erişim adresi: https://megaronjournal.com/tr/jvi.aspx?pdir=meg aron\&plng=tur\&un=MEGARON -51423

Albayrak, U., Canbaz, M., \& Albayrak, G. (2015). A rapid seismic risk assessment method for existing building stock in urban areas. Procedia Engineering, 118, 1242-1249. doi: http://doi:10.1016/j.proeng. $\underline{2015.08 .476}$

Altunel, E. ve Barka, A. (1998). Eskișehir fay zonimun İnönü-Sultandere arasında neotektonik aktivitesi. Türkiye Jeoloji Bülteni. 41. 41-52. Erişim adresi: https://www.jmo.org.tr/resimler/ekler/1e7637e7 b6a9f27 ek.pdf?dergi=T\%DCRK\%DDYE\%20JEOLOI \%DD\%20B\%DCLTEN\%DD
Bingöl, E., Akyürek, B. ve Korkmazer, B. (1973). Biga Yarımadası'nın jeolojisi ve Karakaya Formasyonu'nun bazı özellikleri. Cumhuriyetin 50. Yılı Yerbilimleri Kongresi Bildiriler Kitabı, MTA Yayınları, s. 70-77.

Duman, T.Y., \& Emre, Ö. (2013). The East Anatolian Fault: geometry, segmentation and jog characteristics. Geological Society, London, Special Publications 372. doi: https://doi.org/10.1144/ $\underline{\text { SP372.14 }}$

Ergünay, O. (2007). Türkiye'nin afet profili. TMMOB Afet Sempozyumu. 1-14.

Fraser, J., Hubert, G., Ferrari, A., Verbeeck, K., GarciaMoreno, D., Avşar, U., Maricq, N., Coudijzer, A., Vlamynck, N., \& Venneste K. (2012), A 3000-year record of surface-rupturing earthquakes at Günalan:variable fault-rupture lengths along the 1939 Erzincan earthquake-rupture segment of the North Anatolian Fault, Turkey, Annals of Geophysics, 55(5), 895-927. doi: https://doi.org/10.4401/ag$\underline{4884}$

Gözler, M.Z., Cevher, F. ve Küçükyaman, A., 1984. Eskişehir civarının jeolojisi ve sıcak su kaynakları. MTA Dergisi, 103,40-54. Erişim adresi: https://dergi.mta.gov.tr/index.php?id=makalegor\& dil=tr\&mid=509

Güler, E. ve Afacan, K.B., (2019). Yeni Deprem Yönetmeliği performansının zemin büyütme analizi ile belirlenmesi. 5. International Conference on Earthquake Engineering and Seismology Kongresinde Sunulmuş Bildiri, Ankara.

Güler, E., Canbaz M. ve Şengel H.S., (2019). Betonarme ve Yığma Binalarda Kentsel Dönüșüm Uygulamaları: Kütahya Örneği, Eskișehir Osmangazi Üniversitesi Mühendislik ve Mimarlık Fakültesi Dergisi, 27 (5), 6066. doi: https://doi.org/10.31796/ogummf.543246

Hubert-Ferrari, A., Avşar, U., El-Ouahabi, M., Lepoint, G., Martinez, P., \& Fagel N. (2012), Paleoseismic record obtained by coring a sag-pond along the North Anatolian Fault (Turkey), Annals of Geophysics, 55(5), 929-953. doi: https://doi.org/10.4401/ag-5460

Sesetyan, K., Demircioğlu, M.B., Duman, T.Y., Çan, T., Tekin, S., Azak, T.E., \& Fercan, Ö.Z. (2018). A probabilistic seismic hazard assessment for the Turkish territory-part I: the area source model. Bull Earthquake Eng. 16, 3367-3397. doi: https://doi.org/10.1007/s10518-016-0005-6

Şenel, Ş.M., İnel, M., Toprak, S. ve Manav, Y., (2007). Depremde oluşacak bina hasarlarının envarter bilgilerine dayalı tahmini, Altıncı Ulusal Deprem Mühendisliği Konferansı. 245-256. Erişim adresi: http://www.imo.org.tr/resimler/ekutuphane/pdf/ 2576.pdf 
Ünal, O. ve Yurtcu, Ş., (2006). Binaların deprem risk değerlendirmesi için anket çalışması. Yapı Teknolojileri Elektronik Dergisi. 2006:2, 17-22. Erişim adresi: https://www.semanticscholar.org/

Zabcı, C., Akyüz, H.S., Karabacak, V., Sançar, T., Altunel, E., Gürsoy, H., \& Tatar, O. (2011), Palaeoearthquakes on the Kelkit Valley Segment of the North Anatolian Fault, Turkey: Implications for the Surface Rupture of the Historical 17 August 1668 Earthquake, Turkish Journal of Earth Sciences, 20(4), 411-427. doi: https://doi.org/10.3906/yer-0910-48

Zabcı, C., Altunel, E. ve Akyüz, H.S. (2017). Mevcut paleosismolojik veriler ışığında Kuzey Anadolu Fay Zonu'nun dünü ve bugünü. 4. Uluslararası Deprem Mühendisliği ve Sismoloji Konferansı Kongresinde Sunulmuş Bildiri, Eskişehir.

Campbell, K.W., \& Bozorgnia, Y., NGA ground motion model for the geometric mean horizontal component of PGA, PGV, PGD and 5\% damped linear elastic response spectra for periods ranging from 0.01 to 10s, Earthquake Spectra, 24(1), 2008, pp. 139-171. doi: https://doi.org/10.1193/1.2857546

Wald, D.J., Quitariano, V., Heaton, T.H., Kanamori, H., Scrivner, C.W., \& Worden, C.B., Trinet shake maps: rapid generation of peak ground motion and intensity maps for earthquakes in Southern California, Earthquake Spectra, 15, 1999, pp. 537555. doi: https://doi.org/10.1193/1.1586058

İnternet kaynakları (İK)

1. Sivrihisar haritası. (2020). Erişim adresi: https://www.google.com/maps/place/Sivrihisar

2. Sivrihisar İlçesi'nin genel görünümü. (2020). Erişim adresi: http://sivrihisar.bel.tr/tr/sivrihisar/sivrihisar$\underline{\text { tarihi }}$ 